\title{
Initial Elastic Stiffness of Bolted Shear Connectors in Steel-Concrete Composite Structures
}

\author{
Chenggong Wang $\mathbb{D}^{1}{ }^{1}$ Diankai Cao, ${ }^{2}$ Xiaoyang Liu, ${ }^{1}$ Yucai Jing, ${ }^{3}$ Wenzhuo Liu, \\ and Guotao Yang $\mathbb{D}^{1}$
}

\author{
${ }^{1}$ School of Civil Engineering, Qingdao University of Technology, Qingdao 266033, China \\ ${ }^{2}$ Shandong Luqiao Group Co., Ltd., Jinan 250014, China \\ ${ }^{3}$ Shandong Hi-Speed Road \& Bridge Group Co., Ltd., Jinan 250014, China \\ ${ }^{4}$ Zhongqing Jian'an Construction Group Co., Ltd., Qingdao 266000, China
}

Correspondence should be addressed to Guotao Yang; yangguotao@qut.edu.cn

Received 7 September 2021; Revised 22 November 2021; Accepted 15 December 2021; Published 6 January 2022

Academic Editor: Chao Hou

Copyright (C) 2022 Chenggong Wang et al. This is an open access article distributed under the Creative Commons Attribution License, which permits unrestricted use, distribution, and reproduction in any medium, provided the original work is properly cited.

\begin{abstract}
Bolted shear connectors have the advantages of being easily fitted and dismantled during construction, the initial elastic stiffness of which has a great influence on the structural performance of the connected composite structures. In this paper, the initial elastic behaviors of three types of bolted shear connectors used in steel-concrete composite structures (i.e., the bolt with nonembedded nut, the bolt with single-embedded nut, and the bolt with double-embedded nuts) are investigated using finite element analysis (FEA). After the FE models are verified against the experimental results in other literature, an extensive parametric study is carried out to investigate the effects of eight parameters of the composite structures on the initial shear stiffness and tension stiffness as well as coupling stiffness. Empirical formulas are subsequently developed for obtaining the initial elastic stiffness of the bolted shear connectors, based on which further FEA is performed. The FEA results are in good agreement with the experimental results, illustrating the effectiveness of the empirical formulas.
\end{abstract}

\section{Introduction}

Steel-concrete composite structures have been widely used in civil engineering for decades because of their outstanding mechanical performances such as high strength and stiffness, strong resistance to impact and seismic loading, and ease of construction, combing the advantages of both component materials. As an essential part of the composite structures, the connector is utilized to connect the steel component and the concrete component, thus enabling the components to work together effectively. Various types of connectors that can enhance the composite action in the composite structures have been proposed, such as stud connectors, rebar connectors, and profiled connectors [1-5]. Due to the good structural performance and freedom of welding procedure, studs are the most popular connectors used in composite structures nowadays [6-9]. However, the methods currently used for constructing steel-concrete composite structures are usually time-consuming and costly, as the methods require the structures to be accomplished on site by welding studs and casting concrete in situ. Furthermore, since the studs are welded to the upper flange of the steel girders, the dismantlement of the concrete slabs is difficult to implement, leading to the crumbling of concrete, causing the waste of resources and environmental pollution. Therefore, the deconstructable bolted shear connectors (see Figure 1) are proposed, by which dry and wet assembling and high efficient installation can be achieved and the concrete slabs can be easily removed at the end of the structure's service life.

The bolted shear connector is an emerging connection type, rarely used in steel-concrete composite structures in the past. There are fewer studies on bolted shear connectors than those on studs, although they can be easily dismantled 


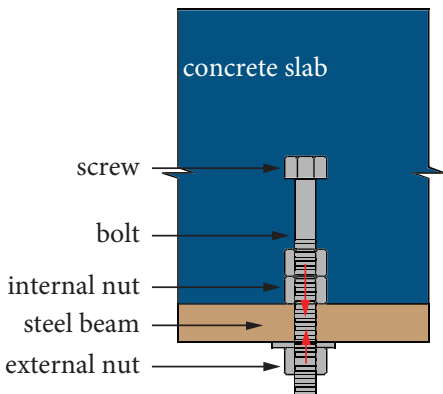

(a)

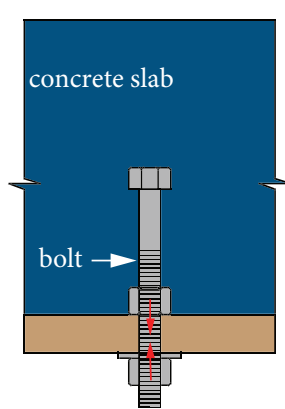

(b)

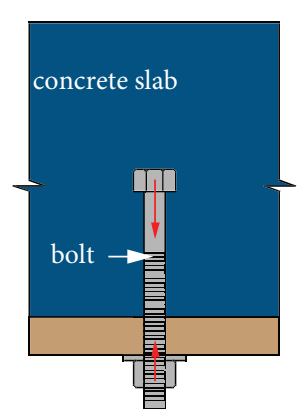

(c)

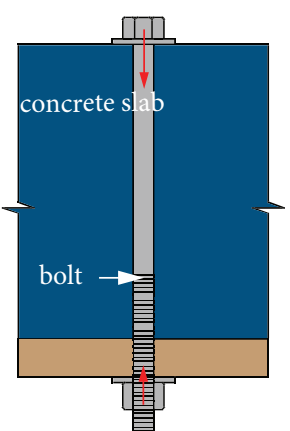

(d)

FIGURE 1: Bolted shear connectors: (a) double-embedded nuts; (b) single-embedded nut; (c) without embedded nut; (d) friction-grip bolt.

in the steel-concrete composite structures. With the development of construction methods, bolted shear connectors are increasingly used to replace studs and other connectors, making the dismantling work easier. Most of the existing references [10-13] concentrated on the fundamental structural behaviors of different types of bolts, such as ultimate capacity, load-slip behavior, and failure mode. Dallam [14] conducted studies on the slip and shear resistance of bolted shear connectors. In order to achieve deconstruction, Kwon et al. $[15,16]$ studied three types of shear connectors, namely, Double-Nut Bolt, High-Tension Friction-Grip Bolt, and Adhesive Anchor connectors, to investigate their static and fatigue strength for application in strengthening noncomposite floor systems. It was concluded that these postinstalled shear connectors showed higher fatigue strength than those of stud shear connectors. In the works of Pavlović et al. $[17,18]$, comparisons between the bolts with singleembedded nut [Figure 1(b)] and headed studs were analyzed to better understand the failure mode of these connectors, the results showed that the bolted shear connectors were similar to headed studs in terms of shear resistance but the bolts are prone to brittle failure. Subsequently, the effects of bolt diameter and concrete strength on the shear behavior of single-embedded-nut bolts were studied by $\mathrm{Su}$ et al. [19]. Unlike the previous prefabrication method, single-nut bolts installed in the precast concrete slab and then assembly were studied by Ataei et al. [20] and analyzed the effects of bolt size and strength on the ductility, strength degradation, and absorbed energy. Recently, Liu et al. [21] and Chen et al. [22] examined the structural behaviors of double-nut bolts [Figure 1(a)] in the prefabricated steel-concrete composite beams, considering the effects of bolt diameters and constraint conditions of the reserved holes. Ataei et al. [23-26] investigated the use of tensional high-strength friction-grip bolts [Figure 1(c)] in steel-concrete composite structures with geopolymer precast concrete slabs for better performance in environmental protection and sustainability. This kind of bolt was also studied by Chen et al. [27], Liu et al. [28], Marshall et al. [29], and Zhang et al. [30], and the effects of bolt diameter, concrete strength, and bolt pretension on the failure mode, the load-ship characteristics, and the ultimate capacity of the bolts were further analyzed. In addition to the studies where the connectors are subjected to single-axis monotonic loading, the behaviors of connectors under biaxial loading were also studied [31-35]. Tan et al. [34] obtained the properties of three types of demountable connectors under combined shear force and tension force. It was found that the shear capacity was reduced significantly when the combined loading is applied. Apart from these bolted shear connectors, many other novel demountable connectors have also been proposed and utilized in steelconcrete beams [36-41].

In addition to the experimental studies discussed above, efforts have also been made to investigate the mechanical behaviors of bolted shear connectors using FEA [42-46]. Pavlović et al. [17] developed an accurate FE model of steelconcrete composite structures to analyze the structural behaviors such as shear resistance, stiffness, ductility, and failure modes in detail. In order to reduce the solution time, a simplified model in which the bolt and nut were merged into a whole instance without considering the thread was developed by Chen et al. [47]. It was concluded that the shear resistance was positively correlated to concrete strength, bolt diameter, and yield strength. Recently, Zhang et al. [30] conducted a series of parametric studies to further investigate the shear capacity and load-slip behavior of highstrength friction-grip bolts. In the work of Liu et al. [48], the behaviors of high-strength friction-grip bolts in steel-concrete composite beams were studied using a three-dimensional FE model. The results showed that the bolt spacing, degree of shear connection, and diameter of the hole in concrete slabs have significant influences on the ultimate strength of the composite beam. Kwon et al. [49] simulated the behaviors of bolted shear connectors by connector elements to verify the feasibility of postinstalled bolted shear connectors on the noncomposite bridge girders. Subsequently, Chen et al. [27] carried out an FEA of through-bolt shear connectors in a full-scale bridge girder, in which the connectors were modeled with connecting elements to simulate the shear stiffness of shear connectors.

The initial elastic behavior of the bolted shear has a great influence on the stiffness of the entire composite structure, determining the natural frequency of the structure. The literature discussed above mainly focused on the strength and stiffness of the bolts; however, the initial elastic stiffness which is crucial to the joint rigidity is not considered. In the present work, FEA is carried out to investigate the structural behavior of bolted shear connectors in the initial elastic 
stage. Parametric analyses on three types of connectors, i.e., the bolt with nonembedded nut, the bolt with single-embedded nut, and the bolt with double-embedded nuts, are reported. The comparisons between the results of FEA and those of experimental tests show good agreement. Finally, empirical formulas are obtained and further applied to the analysis of steel-concrete composite structures.

\section{Numerical Analysis Model}

The FE software Abaqus is employed to simulate the initial elastic stiffness behavior of the bolted shear connectors. A three-dimensional FE model is created, based on which the initial elastic stiffness of the three types of bolted shear connectors is analyzed. The part mesh, interaction, boundary, and load conditions of the model are described in detail in the following sections.

2.1. Finite Element Model. As can be seen in Figure 2, two bolted shear connectors are installed on both sides of the specimen to connect the steel beam and the concrete slab. The three types of bolted shear connectors are investigated, respectively. Because of the symmetry of the structure, only one-quarter of the specimen composed of the bolt, nut, steel beam, base plate, concrete slab, and reinforcing bar is modeled [see Figure 3(a)]. Except for the reinforcing bar and base plate, all components of the specimen are modeled using three-dimensional solid reduced integration elements C3D8R which prevents shear locking and guarantees reasonable computational cost $[42,50]$. The reinforcing bars and base plate are modeled by two-node linear three-dimensional truss element T3D2 and rigid element R3D4, respectively. As shown in Figures 3(b) and 3(c), the bolt and nut are meshed with the size of $4 \mathrm{~mm} \times 4 \mathrm{~mm} \times 4 \mathrm{~mm}$, around which the concrete and steel are meshed with the size of $20 \mathrm{~mm} \times 20 \mathrm{~mm} \times 4 \mathrm{~mm}$ while the size of the remaining element is $20 \mathrm{~mm} \times 20 \mathrm{~mm} \times 20 \mathrm{~mm}$, ensuring the calculation effectiveness. Besides, the base plate is meshed with the size of $20 \mathrm{~mm} \times 20 \mathrm{~mm}$.

Contact nonlinearity is one of the common reasons that make the analysis difficult to converge. Therefore, further simplification is applied to the thread of bolt shank, bolt head, and nut in the FE model. General surface to surface contact interaction is used for contacting the steel beam and bolt as well as the steel beam and nut, and the friction coefficient with the value of 0.4 is adopted [51]. The HARD options are applied for the contact modeling between two surfaces in normal directions while the PENALTY options are used for the tangential behavior. Zero friction is assumed for the contact pair of concrete slab and steel beam. The concrete slab and the part of the bolt and nut embedded in the concrete slab are tied together to eliminate relative slip. Besides, the relative slip and cohesive action between the concrete slabs and rebars are ignored. The surrounding surface of the local concrete part is fully constrained to the reference point as shown in Figure 3(b), and then all directions are constrained in the reference point.

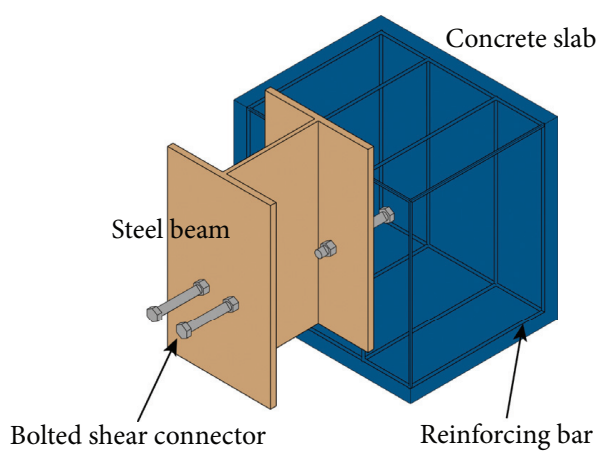

FIgURE 2: The components of the specimen.

For the one-quarter model, symmetric boundary conditions are defined. For the surface of the steel beam and concrete slab (Y-Z plane), the displacement along $X$-axis and the rotations about $Y$ and $Z$ axes $(U 1=\mathrm{UR} 2=\mathrm{UR} 3=0)$ are constrained. For the cross section of the steel beam flange (X-Y plane), the displacement along $Z$-axis and the rotations about $X$ and $Y$ axes $(U 3=\mathrm{UR} 1=\mathrm{UR} 2=0)$ are constrained. To restrain the displacements and rotations in all directions, the bottom of the concrete slab is connected to the base plate through a referent point. All the displacements and rotations related to the $\mathrm{X}-\mathrm{Z}$ plane are constrained $(U 1=\mathrm{U} 2=U 3=\mathrm{UR} 1=\mathrm{UR} 2=\mathrm{UR} 3=0)$. The boundary conditions of the model are shown in Figure 3(b).

The analysis is divided into two steps. In the first step, bolt pretension is applied to the initial surface of the bolt, and the load is then imposed on the whole structure in the second step. For the case where only the shear force is considered, the vertical load is applied to the top of the steel beam by applying pressure. When both the shear and tension forces are considered, the shear force is applied to the top of the steel beam and the transverse horizontal load is applied to the region of the concrete slab. The loading conditions are shown in Figure 3(b).

2.2. Validation of Test Results. The stiffness formulas of the two cases discussed above are derived as follows. In the first case, only the shear force $V$ is considered: $N=\Delta N=0$ and $V=\Delta V$. In the second case, because both the shear and tension forces are considered, $N=\Delta N$ and $V=\Delta V$. The basic matrix formula can be formulated as

$$
\left\{\begin{array}{c}
\Delta V \\
\Delta N
\end{array}\right\}=\left[\begin{array}{ll}
K_{V} & K_{C} \\
K_{C} & K_{N}
\end{array}\right]\left\{\begin{array}{l}
\delta v \\
\delta u
\end{array}\right\},
$$

where $K_{\mathrm{N}}, K_{\mathrm{C}}$, and $K_{\mathrm{V}}$ represent the initial tension stiffness, initial coupling stiffness, and initial shear stiffness, respectively, as shown below:

$$
\begin{aligned}
& K_{N}=\frac{\Delta N_{2}}{\delta u_{2}-\delta v_{2} / \delta v_{1} \delta u_{1}} \\
& K_{C}=-\frac{K_{N} \delta u_{1}}{\delta v_{1}} \\
& K_{V}=\frac{\Delta V_{1}-K_{C} \delta u_{1}}{\delta v_{1}} .
\end{aligned}
$$




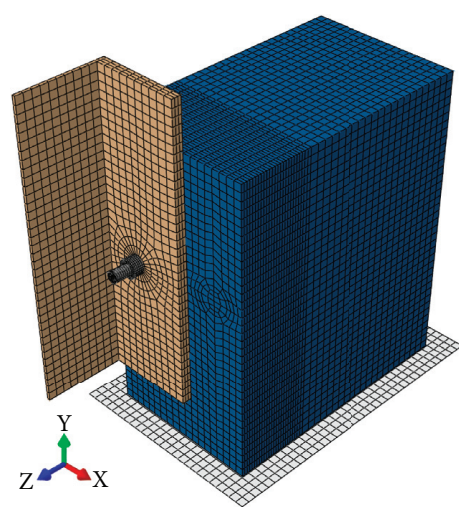

(a)

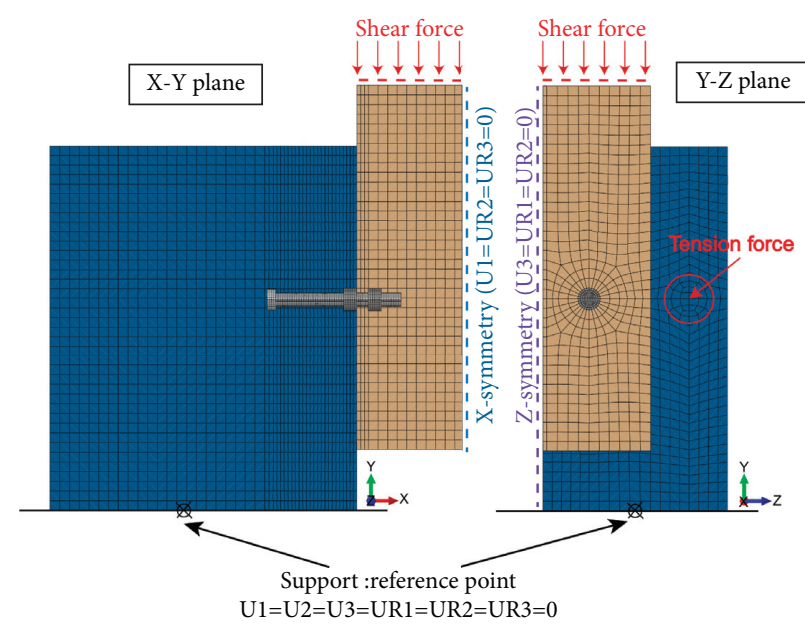

(b)

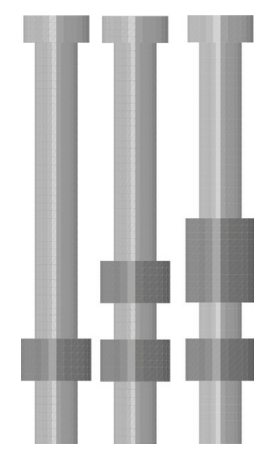

(c)

FIgURE 3: The FE model: (a) one-quarter of the model; (b) the boundary and loading conditions; (c) bolted shear connectors.

It should be noted that the stiffness matrix is considered as a symmetric matrix in this paper. In this study, the specimen of the push-out test is investigated using FEA. The dimension of the concrete slab is $600 \mathrm{~mm} \times 600 \mathrm{~mm} \times 500 \mathrm{~mm}$. The length of the steel beam with section $350 \mathrm{~mm} \times 350 \mathrm{~mm} \quad \times$ $12 \mathrm{~mm} \times 19 \mathrm{~mm}$ is $600 \mathrm{~mm}$. The diameter of the rebar is $20 \mathrm{~mm}$. To validate the accuracy of the FE model, the FE results are verified by existing experimental results. The bolt with a singleembedded nut (SENB) proposed in the work of Ataei et al. [20] is selected for comparison. The specimen consists of two concrete slabs on each side of the steel flange, for which the SENB is used to make these components into a whole. A pretension load with the value of $50 \%$ of the ultimate load capacity is applied to the bolt shank. The bolts with doubleembedded nuts (DENB) used in the work of Chen et al. [22] are selected for further validation for which the bolt and nut are merged to form a single instance. In the work of Tan et al. [34], the structural behaviors of three types of demountable connectors (i.e., AJAX ONESIDE, threaded headed stud, and Hollo-Bolt) under combined shear and tension forces were investigated, and the threaded headed stud is treated as NENB. Dimensions and material properties are shown in Tables 1 and 2 , respectively. Comparisons between the numerical results and the test results are shown in Table 3. It can be seen that the obtained results of the experimental tests are slightly higher than those of the FEA. For the same bolt size, the SENB and DENB have similar values of shear stiffnesses which are higher than those of the NENB. Therefore, the embedded nut in composite structures indeed affects the stiffness of the bolts. It can be seen from Table 3 that the FE results are in good agreement with the experiment results; hence, this FE model is capable of simulating the stiffness of the bolted shear connectors.

\section{Parametric Study}

A parametric study is performed in this section to investigate the effects of eight proposed factors on the initial elastic stiffness of the three types of bolted shear connectors. Firstly, the initial elastic stiffness of the bolted shear connectors subjected to shear loading is studied. After that, the initial stiffness is further explored for the case where coupled loading condition is applied.

3.1. Influence of Bolted Shear Connectors. The initial elastic stiffness of the bolted shear connectors reflects the deformability of the bolt, which is regarded as an indicator to evaluate the overall performance of the steel-concrete composite structures. Based on the results of FEA, the influence of the bolt length, the bolt diameter, the elastic modulus of the bolt, and the pretension force in the bolt are presented in Figure 4 and Figures 5 in 6, respectively.

It can be seen from Figures 4(a) and 5(a) that the initial shear stiffness and tension stiffness are positively correlated to the bolt diameter; as can be seen from Figure 6(a), the relationship between coupling stiffness and bolt diameter is also positive. It should be noted that the DENB has the highest coupling stiffness, shear stiffness, and tensile stiffness than the others, reflecting the advantages of double-embedded nuts. In addition, for these results, the effects of the sizes of the bolt head and nut should be taken into account, as they change with bolt diameter.

It can be seen from Figures 4(b), 5(b), and 6(b) that the variation of bolt length has a slight influence on the initial elastic stiffness of these connectors. The NENB has the lowest shear, tensile, and coupling stiffness, while DENB is the opposite precisely. The shear and tension stiffnesses of the SENB and DENB which are embedded with nut are more than 2.5 and 1.5 times higher than those of the NENB, respectively. However, the coupling stiffness of the NENB is 3 times higher than that of the SENB and DENB.

The change of elastic modulus of the bolt has a remarkable influence on the initial elastic stiffness. As shown in Figures 4(c) and 5(c), the shear and tension stiffnesses are positively associated with the elastic modulus of the bolt. The SENB and DENB possess almost the same shear stiffness, but the DENB has higher tension stiffness. It can be seen from Figure 6(c) that the coupling stiffness is positively correlated 
TABLE 1: Dimensions of the specimens.

\begin{tabular}{|c|c|c|c|c|c|c|}
\hline & \multirow{2}{*}{ Steel beam (mm) } & \multirow{2}{*}{ Concrete slab $(\mathrm{mm})$} & \multirow{2}{*}{$\operatorname{Bar}(\mathrm{mm})$} & \multicolumn{2}{|c|}{ Bolt (mm) } & \multirow{2}{*}{ Type } \\
\hline & & & & Diameter & Length & \\
\hline Ataei et al. [20] & IPE270 $(270 \times 135 \times 6.6 \times 10)$ & $500 \times 500 \times 120$ & 12 & $\begin{array}{l}12 \\
16 \\
20\end{array}$ & $\begin{array}{l}100 \\
100 \\
100\end{array}$ & SENB \\
\hline Chen et al. [22] & $250 \times 250 \times 14 \times 9$ & $460 \times 460 \times 150$ & 10 & $\begin{array}{l}12 \\
16\end{array}$ & $\begin{array}{l}100 \\
100\end{array}$ & DENB \\
\hline Tan et al. [34] & 360UB56.7 & $600 \times 600 \times 150$ & 12 & 19 & 120 & NENB \\
\hline
\end{tabular}

TABLE 2: Material properties.

\begin{tabular}{lccccc}
\hline & Bolt & Steel & Concrete & Bar & Author \\
\hline \multirow{3}{*}{ Elastic modulus $(\mathrm{GPa})$} & 201 & 201 & 34.5 & 198 & Ataei et al. [20] \\
& 208 & 203 & 31 & 176 & Chen et al. [22] \\
& 206 & 226 & 34.667 & 200 & Tan et al. [34] \\
\hline
\end{tabular}

TABle 3: Comparisons between FE results and experimental results.

\begin{tabular}{lccccc}
\hline & Bolt diameter $(\mathrm{mm})$ & Push-out test $(\mathrm{kN} / \mathrm{mm})$ & FE model $(\mathrm{kN} / \mathrm{mm})$ & FE model/push-out test & Remark \\
\hline \multirow{2}{*}{ Ataei et al. [20] } & 12 & 1118.229 & 1057.439 & 1258.878 & 0.946 \\
& 16 & 1298.809 & 2049.534 & 0.969 & 0.950 \\
\hline \multirow{2}{*}{ Chen et al. [22] } & 20 & 2157.561 & 996.507 & 0.908 \\
& 12 & 1097.426 & 1357.673 & 0.859 & SENB \\
\hline Tan et al. [34] & 16 & 1579.977 & 793.033 & 0.973 \\
\hline
\end{tabular}

to the elastic modulus of the bolt. The NENB achieves the lowest coupling, shear, and tension stiffnesses. Besides, for tension and coupling stiffnesses, the SENB and DENB are more sensitive to the change of elastic modulus than the NENB.

To evaluate the effects of the pretension force on the initial elastic stiffness, five degrees of pretension force are applied to the bolt. The shear and coupling stiffnesses of the NENB are not sensitive to the pretension force and remain unchanged as can be seen from Figures 4(d) and 6(d), while the shear stiffnesses and coupling stiffnesses of the rest connectors with embedded nut are positively correlated to the pretension force. The tension stiffness decreases significantly when the bolt pretension is applied, as shown in Figure 5(d); the tension stiffness of the SENB is slightly lower than that of the DENB. The NENB has the lowest shear stiffness and tension stiffness, and its coupling stiffness is more than 3.5 times lower than that of the other two connectors as shown in Figure 6(d).

3.2. Influence of Elastic Modulus of Concrete. In this part, the effects of different elastic modulus of concrete, namely, $30000,32500,34500,36000$, and $37000 \mathrm{~N} / \mathrm{mm}^{2}$, on the initial elastic stiffness are studied. Figures $4(\mathrm{e})$ and 5(e) show that, with the increase of the elastic modulus of concrete, the shear and tension stiffnesses increase slightly. The shear stiffnesses of the SENB and DENB are almost the same but the DENB achieves higher tension stiffness. As can be seen from Figure 6(e), the coupling stiffnesses of the SENB and DENB increase slightly as the elastic modulus of concrete increases; however, the coupling stiffness of the NENB is not sensitive to the elastic modulus of concrete and the magnitude of the change can be ignored.

3.3. Influence of Elastic Modulus of Steel. The effects of elastic modulus of steel from $201 \mathrm{GPa}$ to $221 \mathrm{GPa}$ are investigated. As can be seen from Figures 4(f), 5(f), and 6(f), the elastic modulus of steel almost does not affect the stiffness. The NENB has the lowest shear, tension, and coupling stiffnesses in the comparisons. The values of shear stiffnesses of the SENB and DENB are close to each other and about 2.5 times higher than those of NENB. Compared with the SENB, the DENB achieves higher tension stiffness and coupling stiffness. As can be seen from Figure 6(f), the coupling stiffness of the NENB is more than 3.5 times lower than that of the SENB and DENB.

3.4. Influence of Tension Force. The degrees of the tension force in the specimen are considered in this part. As can be seen from Figures $4(\mathrm{~g})$ and $5(\mathrm{~g})$, with the tension force increasing from $4.4 \mathrm{kN}$ to $26.4 \mathrm{kN}$, the shear stiffness increases slightly while the tension stiffness increases significantly. As shown in Figure 6(g), the coupling stiffness increases with the tension force increases. The coupling stiffnesses of the SENB and DENB are higher than that of the NENB. With the increase of tension force, the difference between the coupling stiffness of the bolt with embedded nut (SENB and DENB) and that of the bolt without embedded nut (NENB) become larger. 


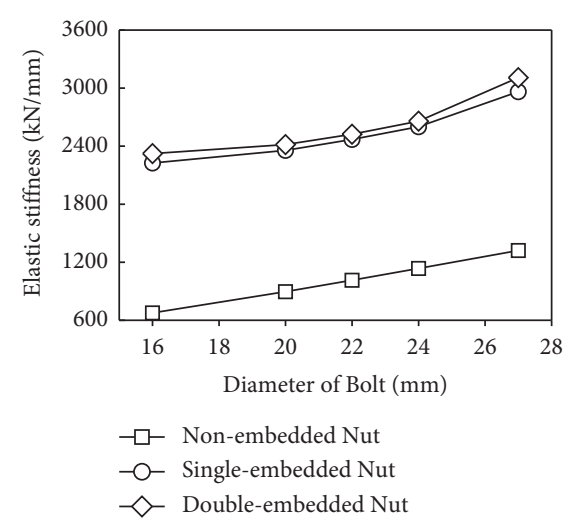

(a)

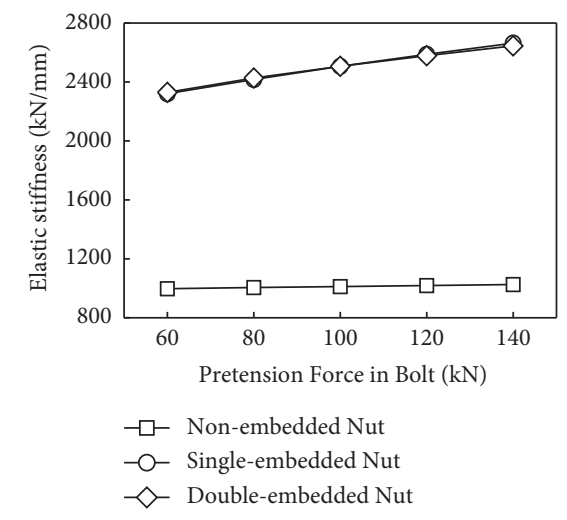

(d)

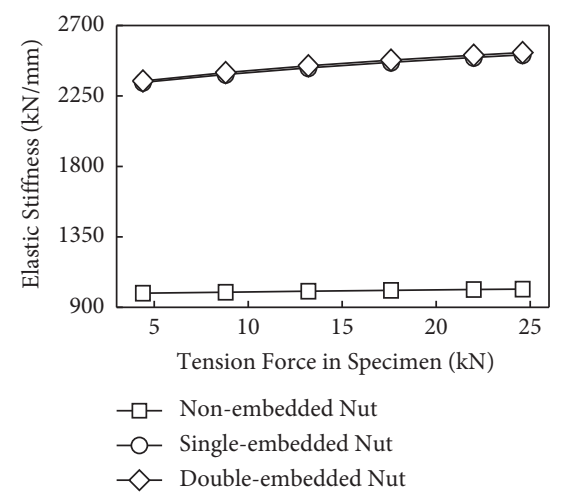

(g)

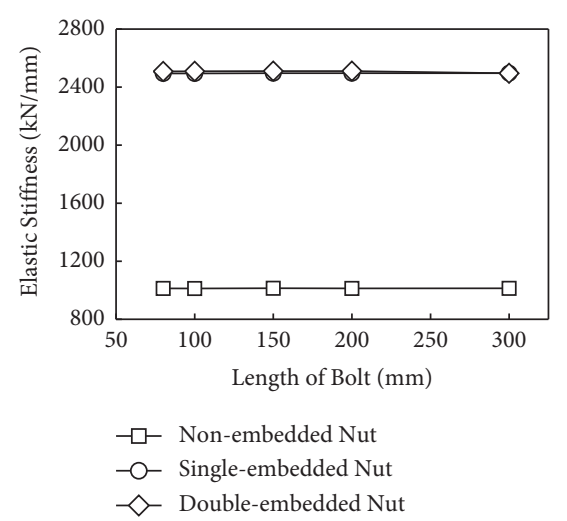

(b)

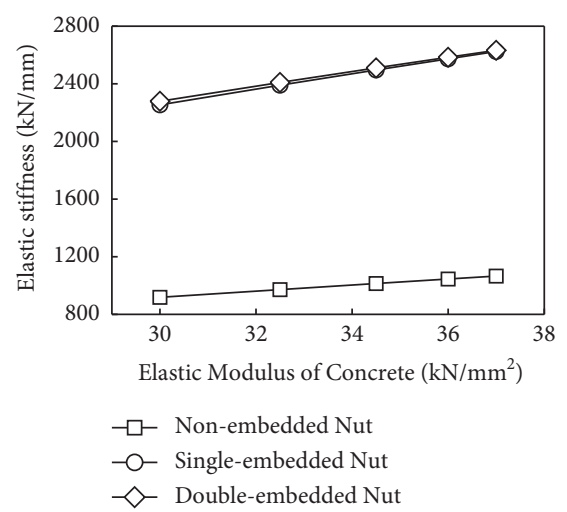

(e)

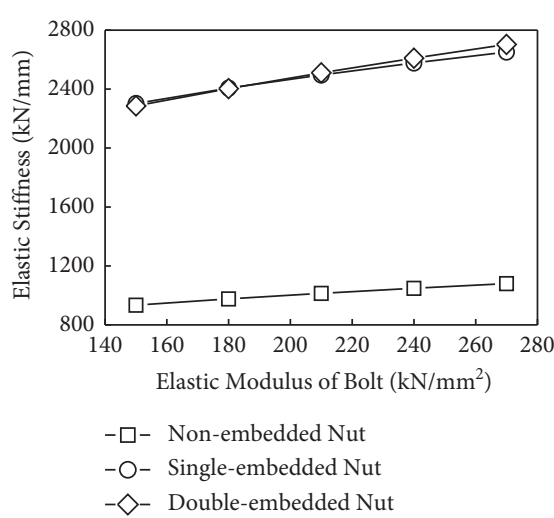

(c)

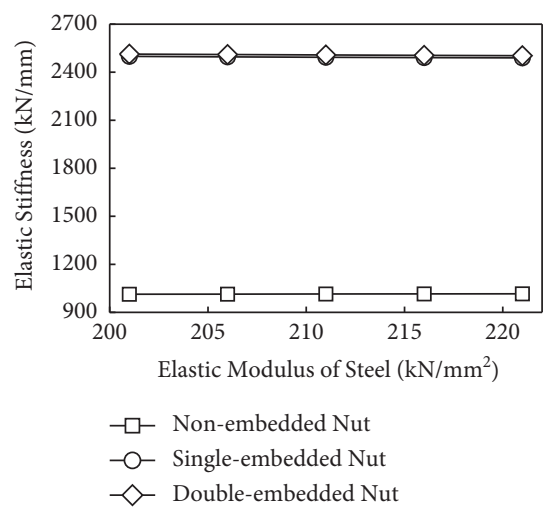

(f)

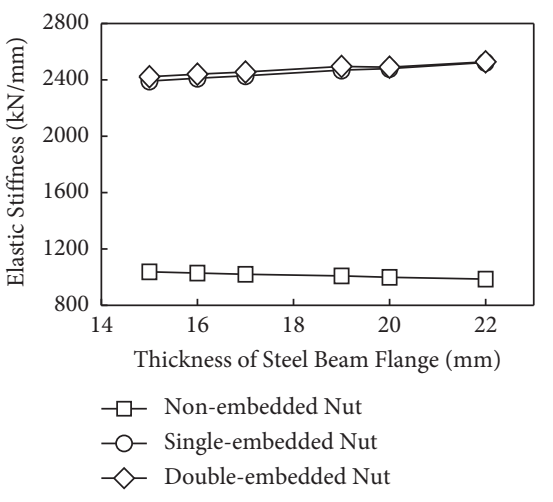

(h)

Figure 4: Initial shear stiffness.

3.5. Influence of the Thickness of the Steel Beam Flange. The effects of the flange thickness on the initial elastic stiffness are also studied. As the flange thickness increases, the contact surface between the preformed hole of the steel beam and the bolt shank becomes larger, which further increases the friction between the steel beam and the bolt. As shown in Figure 4(h), with the thickness increase, there is a slight increase in the shear stiffnesses of the DENB and SENB but a slight decrease in that of the NENB. The reason for this could be that the specimen with an embedded nut provides a higher pretension force than that with a nonembedded nut. As can be seen in Figure 5(h), with the increase of the flange thickness, the tension stiffness decreases slightly, and the tension stiffnesses of the embedded-nut bolts are about 1.5 times higher than those of the NENB. In Figure 6(h), the coupling stiffness decreases slightly with the increase of the flange thickness, and the NENB achieves the lowest coupling stiffness which is about 3.5 times lower than that of the DENB and SENB.

\section{Empirical Equations}

In this section, empirical formulas in terms of bolt diameter $(D)$, the elastic modulus of concrete $\left(E_{\mathrm{c}}\right)$, and the elastic modulus of bolt $\left(E_{\mathrm{b}}\right)$ for obtaining the initial elastic stiffness are developed based on the FEA. The basic form of the formula can be expressed as 


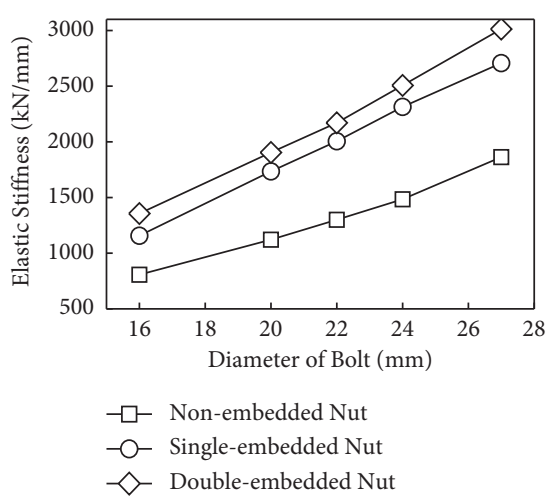

(a)

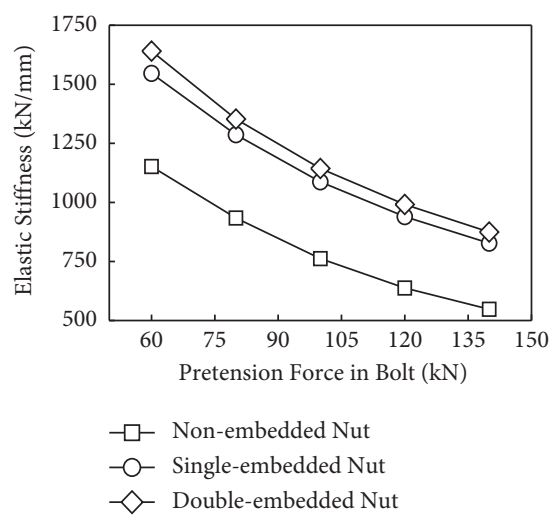

(d)

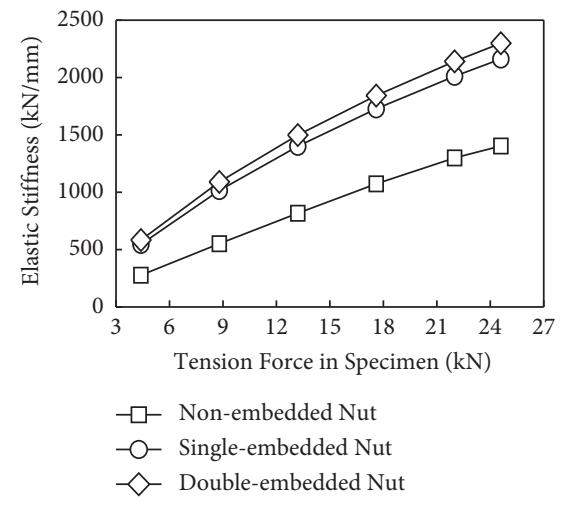

(g)

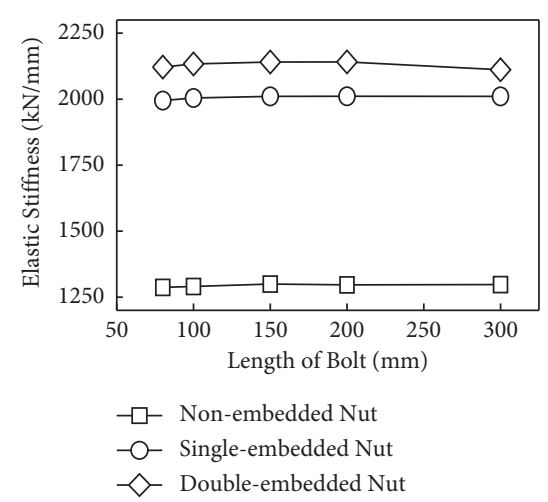

(b)

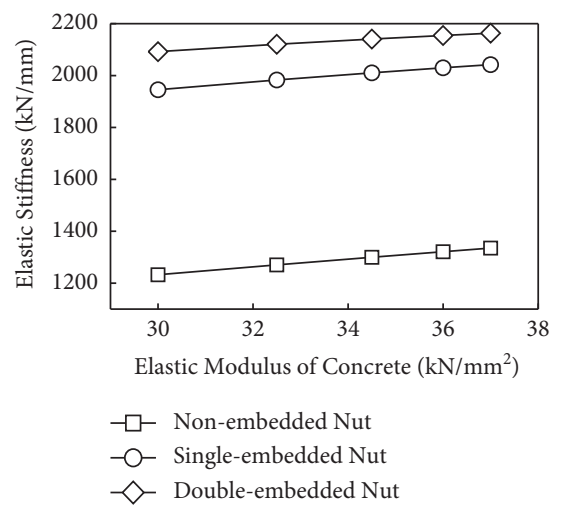

(e)

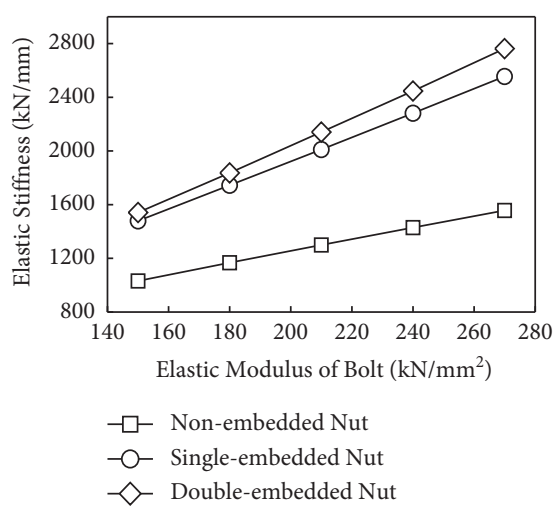

(c)

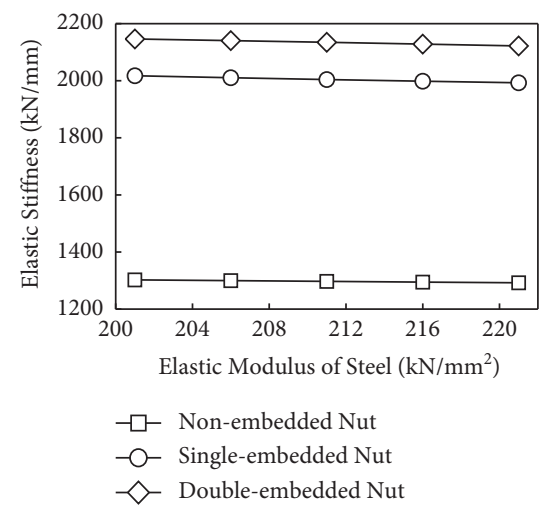

(f)

Figure 5: Initial tension stiffness.

$$
K=\alpha D E_{c}^{\beta} E_{b}^{\lambda}
$$

where $\alpha, \beta$, and $\lambda$ are coefficients obtained from fitting results. The formulas fitted for the three types of bolted shear connectors are shown in Table 4. As Figure 7 shown Figures 8 in 9 , the fitting results are in good agreement with the FEA results.

\section{Applications}

As discussed above, the bolts with embedded nuts (SENB and DENB) achieve better initial elastic stiffness than the bolts with nonembedded nut (NENB). Two examples proposed by Kwon et al. [52] and Du et al. [53] are used herein to further illustrate the applications of the proposed formulas to the DENB and SENB.

5.1. Bolted Shear Connectors with Double-Embedded Nuts. The initial elastic stiffness obtained from the proposed formulas is applied to the example of Kwon et al.'s work [52], in which a simply supported steel-concrete composite beam with double-nut bolts is studied. The details of the beam are shown in Figure 10. The composite beams are designed with a $30 \%$ shear connection ratio, which requires a total of 32 shear connectors in a beam. 


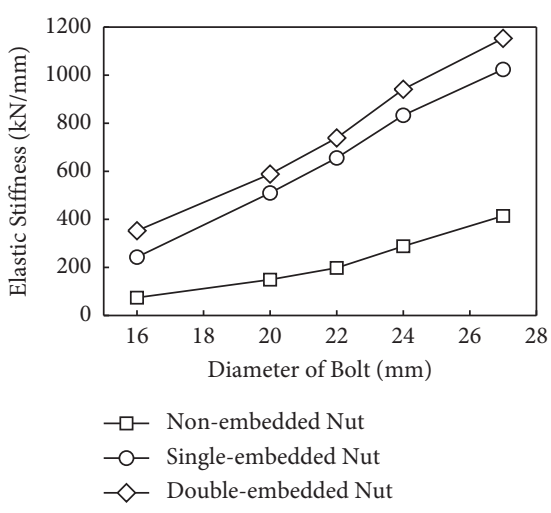

(a)

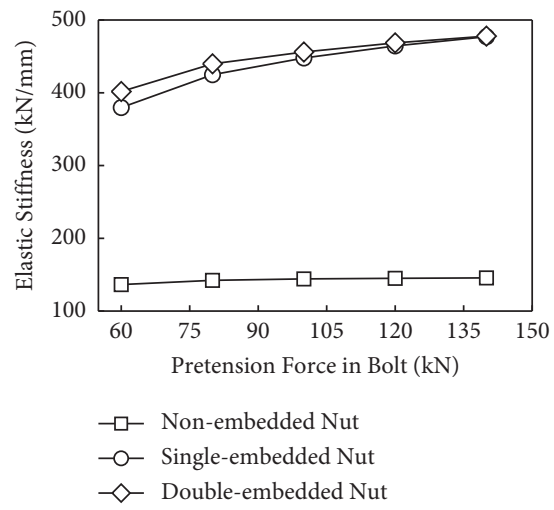

(d)

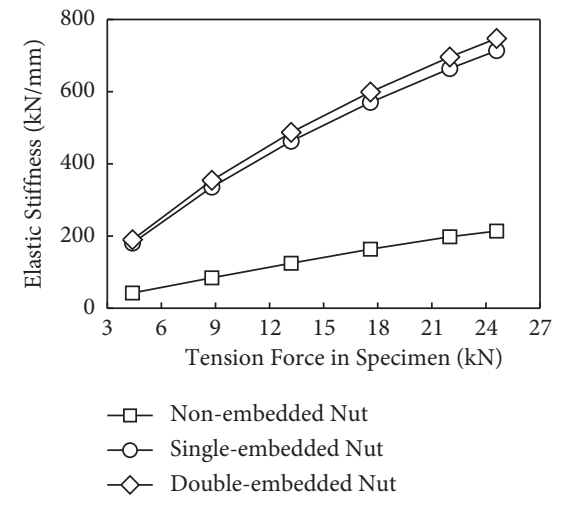

(g)

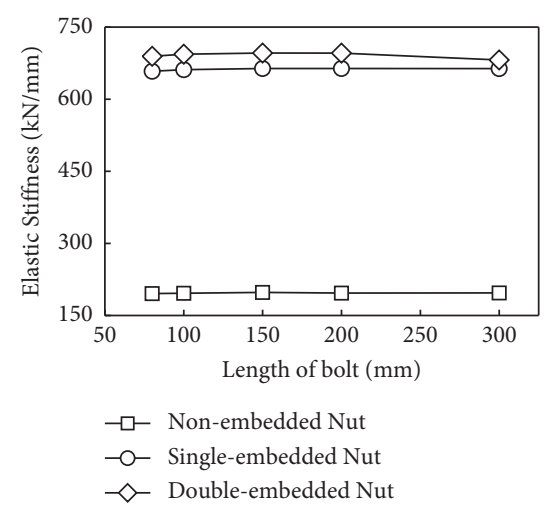

(b)

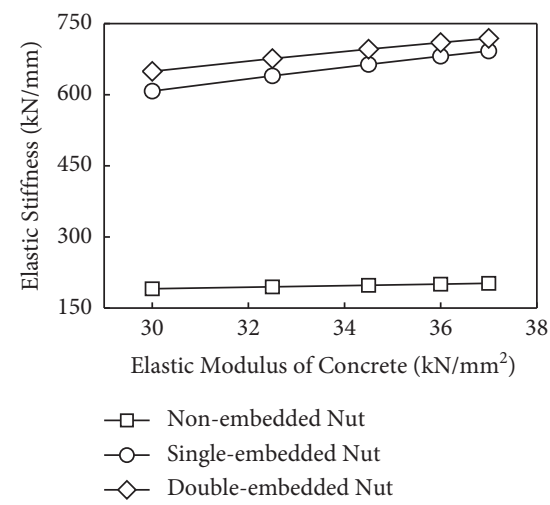

(e)

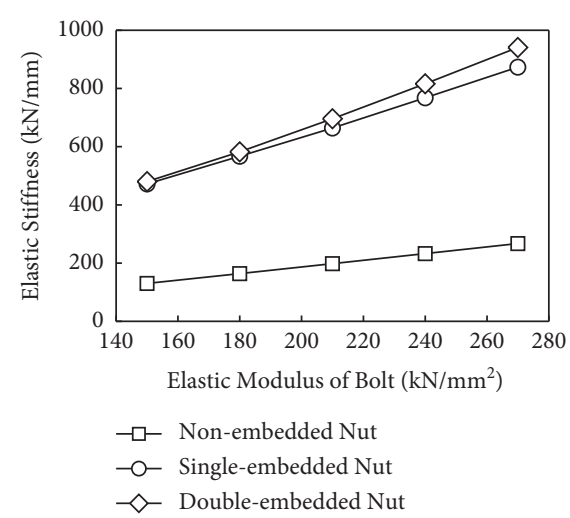

(c)

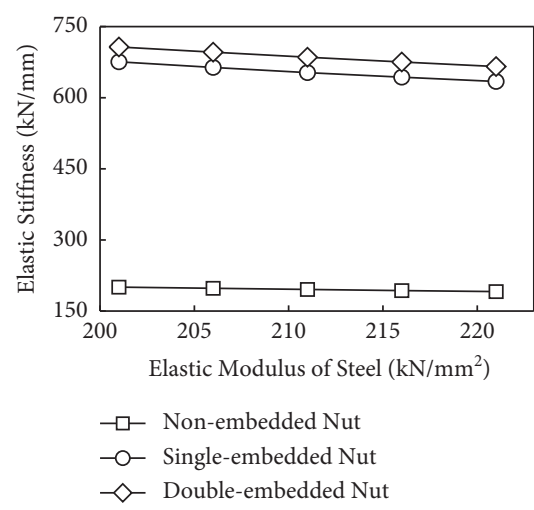

(f)

FIgURE 6: Initial coupling stiffness.

TABLe 4: The empirical formulas.

\begin{tabular}{lccc}
\hline Name & $K_{\mathrm{V}}(\mathrm{kN} / \mathrm{mm})$ & $K_{\mathrm{N}}(\mathrm{kN} / \mathrm{mm})$ & $K_{\mathrm{C}}(\mathrm{kN} / \mathrm{mm})$ \\
\hline NENB & $0.000849 D E_{c}^{0.748} E_{b}^{0.252}$ & $0.0004986 D E_{c}^{0.313} E_{b}^{0.687}$ & $-3.721 D E_{c}^{-0.094} E_{b}^{1.094}$ \\
SENB & $0.00212 D E_{c}^{0.756} E_{b}^{0.244}$ & $0.000509 D E_{c}^{0.086} E_{b}^{0.914}$ & $-0.000149 D E_{c}^{0.0227} E_{b}^{0.9773}$ \\
DENB & $0.00198 D E_{c}^{0.713} E_{b}^{0.287}$ & $0.0004959 D E_{c}^{0.033} E_{b}^{0.967}$ & $-0.000141 D E_{c}^{-0.047} E_{b}^{1.047}$ \\
\hline
\end{tabular}

The stiffness of the bolted shear connector calculated from Table 4 is employed in the finite element analysis. As shown in Figure 11, the 4-node shell element S4R and the 8-node solid element C3D8R are used for the steel beam and concrete slab, respectively. The connectors are employed to connect the concrete slab and steel girder in the FE models. Element connectors are used to measure the deformation capacity by defining a local Cartesian coordinate system [49]. Because this study focuses on the elastic stage, the bracing at the end of the beam is ignored in the model. Besides, the reinforcing bar is embedded in the concrete slab. 


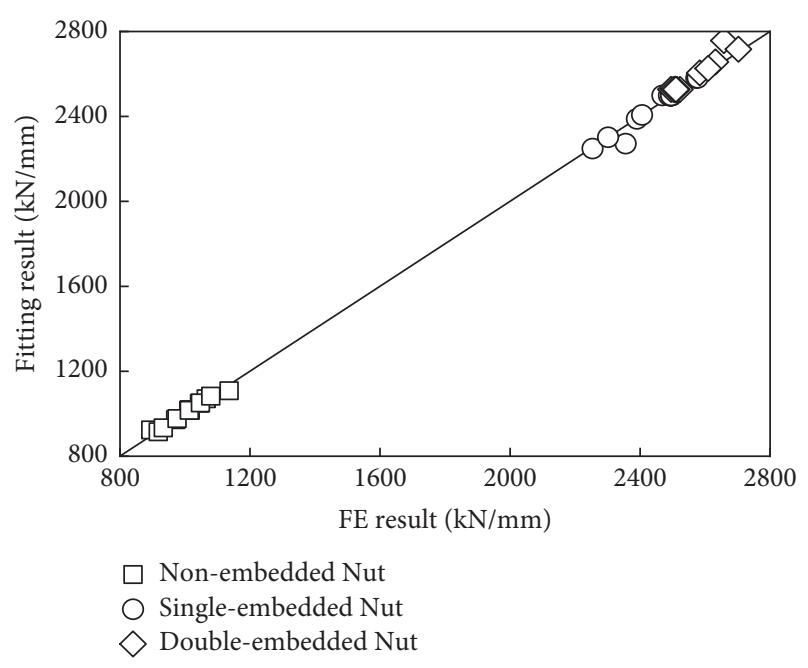

Figure 7: Comparisons of shear stiffness between the FE results and fitting results.

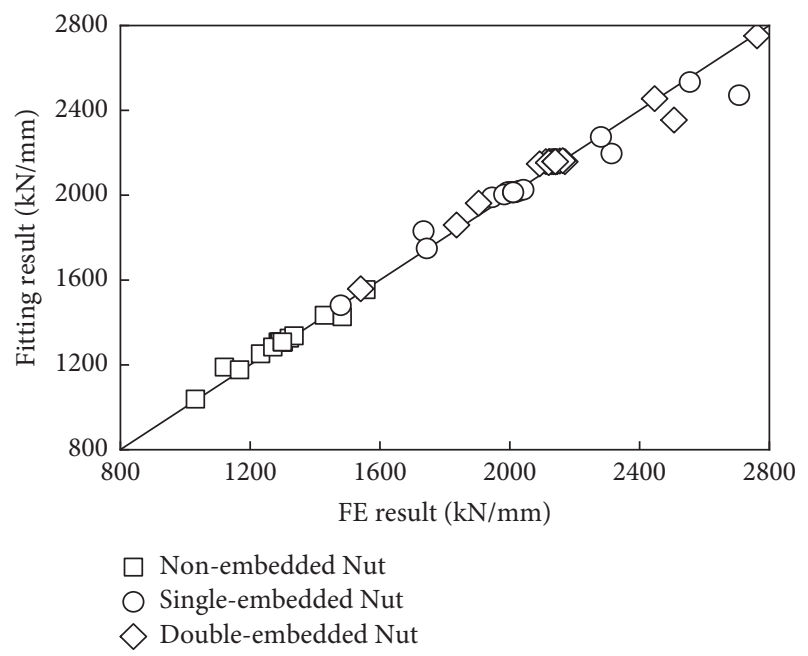

FIGURE 8: Comparisons of tension stiffness between the FE results and fitting results.

When the pressure load is applied to the beam, shear stress and tensile stress are generated on the connectors. Therefore, the tensile stiffness in one direction and the shear stiffness in the other two directions should be studied. According to the calculation formulas, the stiffnesses of the DENB including the shear stiffness $\left(K_{\mathrm{V}}\right)$ and the tension stiffness $\left(K_{\mathrm{N}}\right)$ are obtained: $K_{\mathrm{V}}=2170.520 \quad(\mathrm{kN} / \mathrm{mm})$; $K_{\mathrm{N}}=2143.487(\mathrm{kN} / \mathrm{mm})$.

The specimen is in the elastic stage if the value of load is below $22 \mathrm{kN}$ [52]. Hence, a pressure load of $20 \mathrm{kN}$ is applied in the middle of the composite beam. The material linear elasticity is taken into account during the analysis. As shown in Figure 12, the load-deflection curve obtained by FEA indicates that the result is in good agreement with the test result in the elastic stage, and the correlation coefficient is 0.909 . The FE result is about $10.65 \%$ higher than the test result. The displacements of the 32 connectors under a pressure load of $22 \mathrm{kN}$ are illustrated in Figure 13. Sixteen

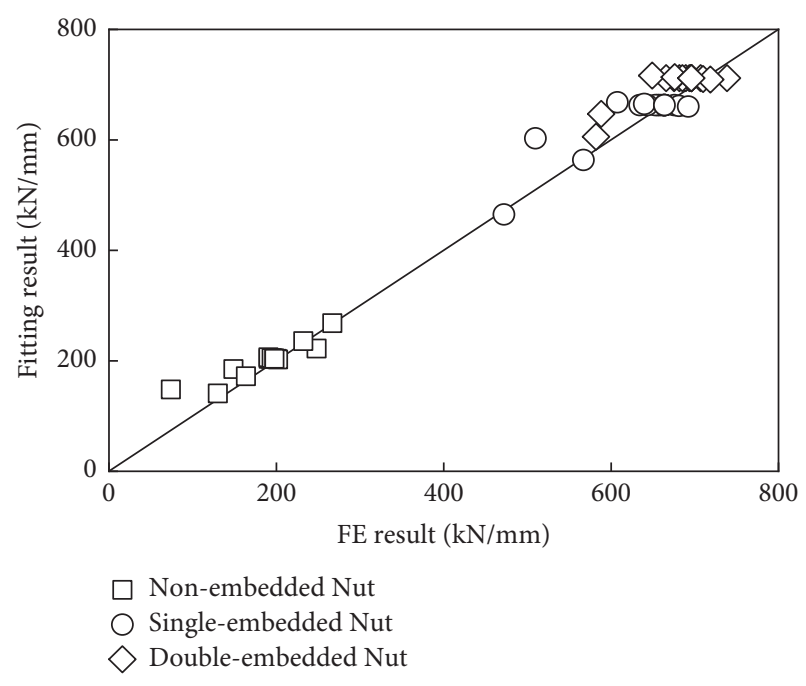

Figure 9: Comparisons of coupling stiffness between the FE results and fitting results.

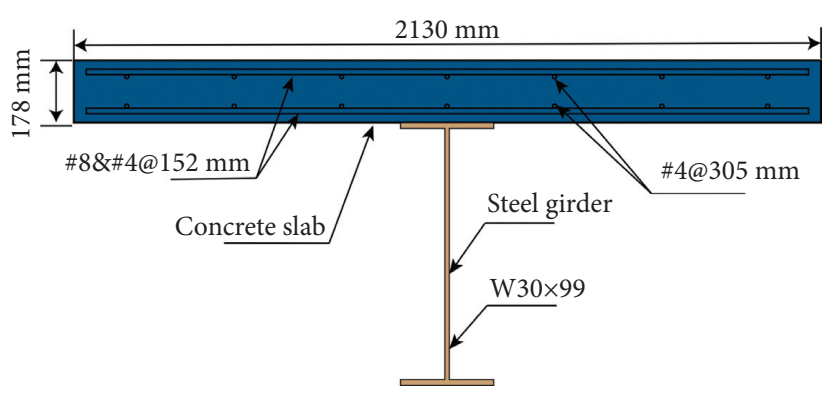

FIgURE 10: The cross section of the composite beams tested by Kwon et al. [52].

pairs of connectors are symmetrically distributed in the composite beam, with 16 connectors assigned in each column. These two symmetrical connectors in each pair have similar displacements. The results in Figure 13 represent the average value of each pair of connectors. As the load is applied to the midspan, the displacement in the middle of the span is the largest, and the displacements at the two supports are the smallest. The displacement increases from the two supports to the middle of the span.

5.2. Bolted Shear Connectors with Single-Embedded Nut. Three precast full-scale steel-concrete composite beams (PCB1, PCB2, and PCB3) with SENB proposed by Du et al. [53] are studied herein. The details of the composite beams are shown in Figure 14. Three different shear connection ratios are applied to the composite beams. A total of forty high-strength bolted shear connectors with full shear connections are used in PCB1. Thirty bolted shear connectors with $68 \%$ shear connection and twenty-two bolted shear connectors with $46 \%$ shear connection are used in PCB2 and PCB3, respectively. As shown in Figure 11, the bolted shear connectors are modeled by element connectors in the FE model where the steel beam and the concrete slab are modeled by the 4-node shell element S4R and the 8-node 


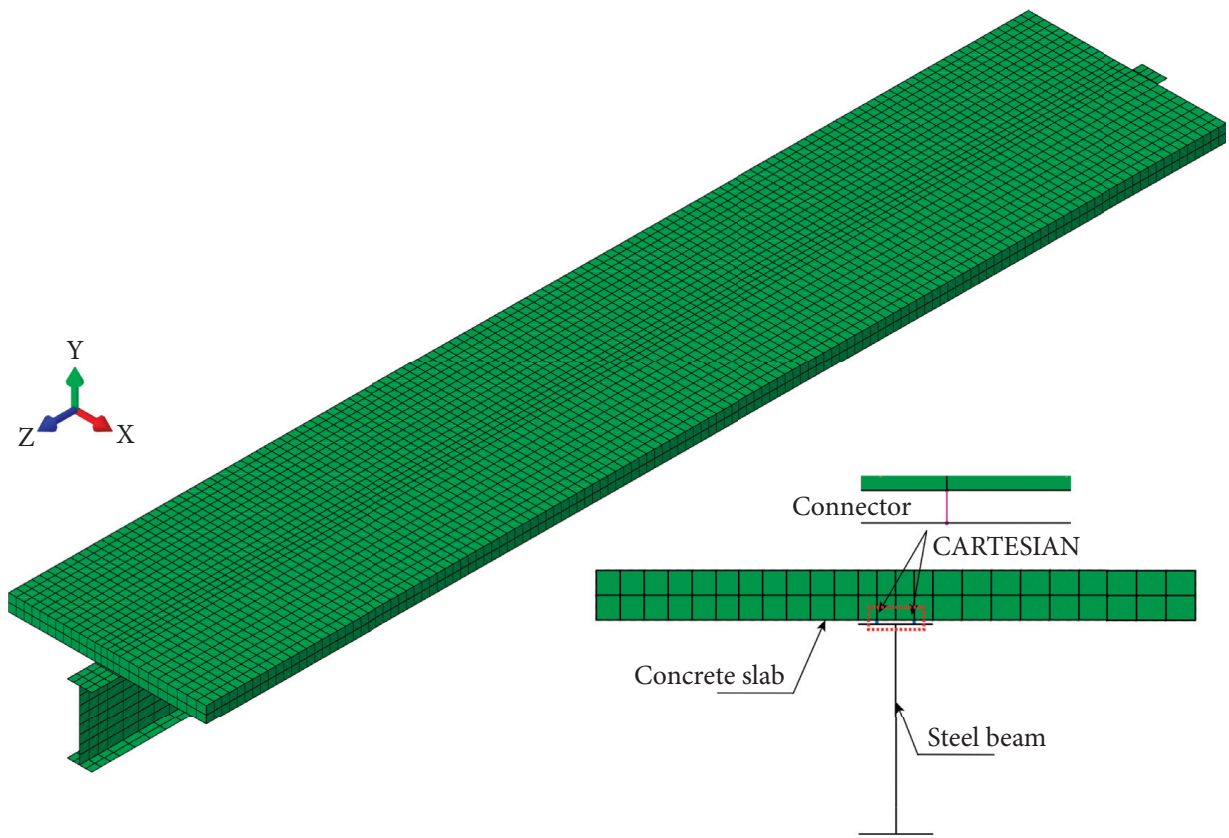

FIgURE 11: FE model of composite beam.

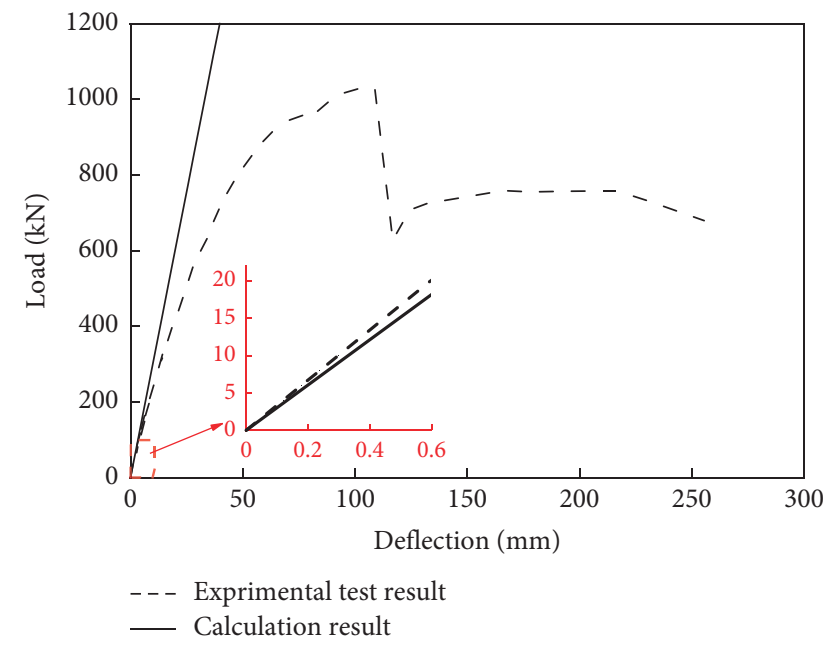

FIGURE 12: Comparisons between the FE results and experimental results.

solid element C3D8R, respectively. The shear stiffness of $2009879.079 \mathrm{~N} / \mathrm{mm}$ and the tension stiffness of $1804816.555 \mathrm{~N} / \mathrm{mm}$ obtained by the proposed formulas are applied to element connectors. Two-point symmetric loading $(20 \mathrm{kN})$ is adopted in the FE model.

The stiffness of the composite beams is significantly influenced by the degree of shear connection. As shown in Figure 15, the full shear connection of PCB1 achieves the highest stiffness compared with the other two shear connections. In general, the test results of PCB1, PCB2, and PCB3 are in good agreement with the FE results, and the correlation coefficients are $0.908,0.969$, and 0.993 , respectively. In Figure 16, the displacements of connectors in the composite beams are presented, which are the average value of the two bolts at symmetrical positions along with the

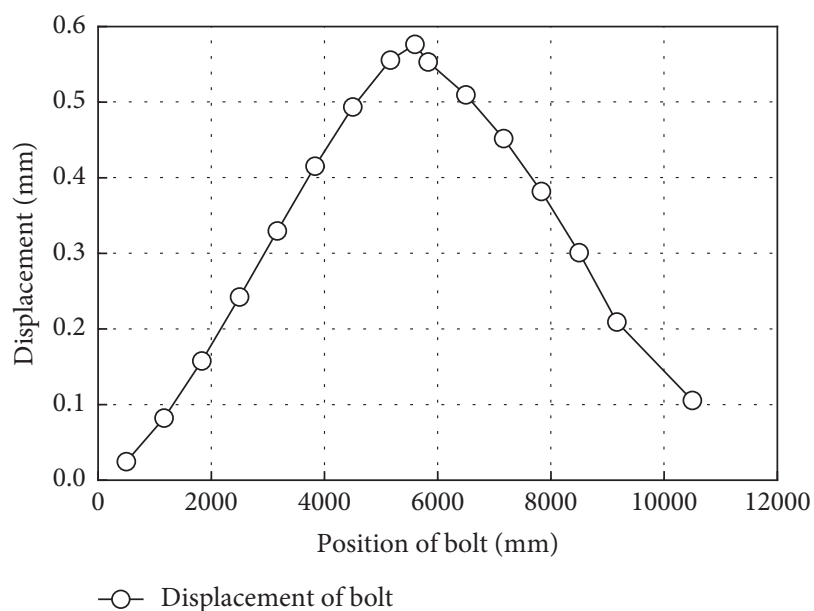

Figure 13: The displacements of the connectors in the elastic stage.

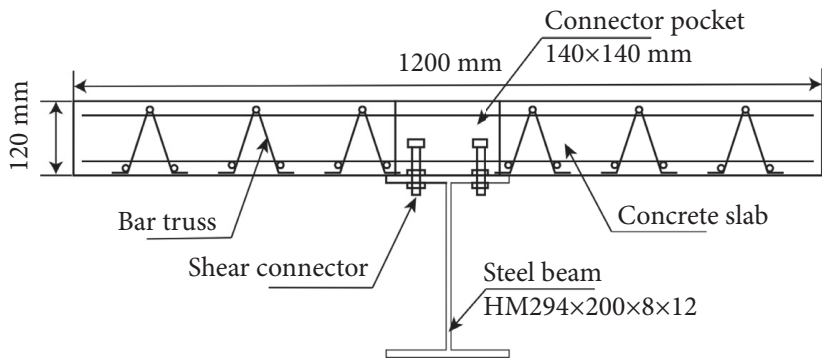

FIgURE 14: The cross section of the composite beams tested by $\mathrm{Du}$ et al. [53].

width of the beam. It can be seen that the displacement decreases as the degree of shear connection increases, and the maximum displacement occurs in the midspan of each composite beam. 

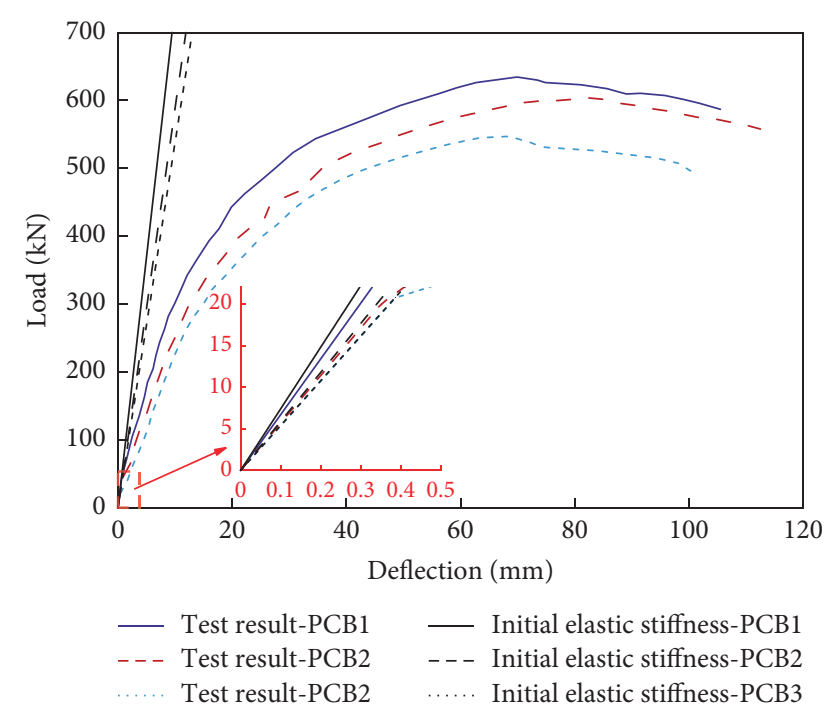

FIgURE 15: Comparisons between the FE results and experimental results.

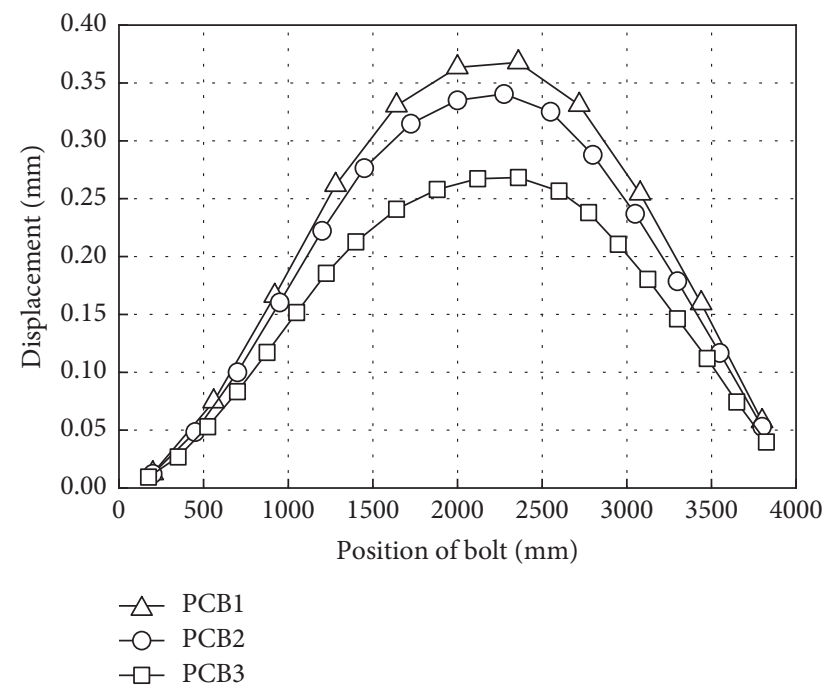

Figure 16: The displacements of beams with different shear connection rates in the elastic stage.

\section{Conclusions}

The initial elastic behaviors of three types of bolted shear connectors under pure shear loading and combined loading of shear and tension are studied. The effects of eight parameters on the initial elastic stiffness of the bolted shear connectors are investigated. The bolts with embedded nuts have a significant impact on the stiffness compared to the bolts with nonembedded nut. In most cases, whether the bolt embedded a single nut or double nuts is irrelevant to initial elastic stiffness, it has a great impact on the stiffness if there is no embedded nut. Because of the existence of the embedded nut, the SENB and DENB have higher shear stiffness and tension stiffness than the NENB, the shear stiffnesses of the three types of bolted shear connectors are positively associated with the bolt diameter, the elastic modulus of the bolt and concrete, and the pretension force in the bolt. Compared with the shear stiffness, the effects of the bolt diameter, the elastic modulus of the bolt, and the degree of tension force on tension stiffness are more significant, and the tension stiffness decreases as the pretension force in the bolt increases. As for the coupling stiffness, the bolt diameter, the elastic modulus of the bolt, the degree of the tension force, and the pretension force in the bolt are the main determining factors. Empirical formulas for obtaining the initial elastic stiffness are also developed, based on which further FEA is performed for the composite beams proposed in $[52,53]$, and the results of the FEA are in good agreement with those of the experimental tests.

\section{Data Availability}

No data were used to support this study.

\section{Conflicts of Interest}

The authors declare that they have no conflicts of interest.

\section{Acknowledgments}

The research was sponsored by the National Natural Science Foundation of China (Nos. 51808308 and 51978351) and State Key Laboratory of Disaster Reduction in Civil Engineering, Tongji University, China (No. SLDRCE17-02).

\section{References}

[1] M. Sjaarda, T. Porter, J. S. West, and S. Walbridge, "Fatigue behavior of welded shear studs in precast composite beams," Journal of Bridge Engineering, vol. 22, no. 11, 2017.

[2] J. Bonilla, L. M. Bezerra, and E. Mirambell, "Resistance of stud shear connectors in composite beams using profiled steel sheeting," Engineering Structures, vol. 187, pp. 478-489, 2019.

[3] C.-S. Shim, P.-G. Lee, and T.-Y. Yoon, "Static behavior of large stud shear connectors," Engineering Structures, vol. 26, no. 12, pp. 1853-1860, 2004.

[4] M. Spremic, Z. Markovic, M. Veljkovic, and D. Budjevac, "Push-out experiments of headed shear studs in group arrangements," Advanced Steel Construction, vol. 9, no. 2, pp. 139-160, 2013.

[5] Y. H. Wang, J. G. Nie, and J. J. Li, "Study on fatigue property of steel-concrete composite beams and studs," Journal of Constructional Steel Research, vol. 94, pp. 1-10, 2014.

[6] B. Zhuang, Y. Liu, and F. Yang, "Experimental and numerical study on deformation performance of rubber-sleeved stud connector under cyclic load," Construction and Building Materials, vol. 192, pp. 179-193, 2018.

[7] F. Yang, Y. Q. Liu, and Y. J. Li, "Push-out tests on large diameter and high strength welded stud connectors," Advances in Civil Engineering, vol. 2018, Article ID 4780759, 2018.

[8] C. Xu, Q. Su, and K. Sugiura, "Mechanism study on the low cycle fatigue behavior of group studs shear connectors in steel-concrete composite bridges," Journal of Constructional Steel Research, vol. 138, pp. 196-207, 2017.

[9] J. N. Qi, J. Q. Wang, M. Li, and L. L. Chen, "Shear capacity of stud shear connectors with initial damage: experiment, FEM 
model and theoretical formulation," Steel and Composite Structures, vol. 25, pp. 79-92, 2017.

[10] Z. Lin, Y. Liu, and J. He, "Behavior of stud connectors under combined shear and tension loads," Engineering Structures, vol. 81, pp. 362-376, 2014.

[11] A. Shariati, M. Shariati, N. H. Ramli Sulong, M. Suhatril, M. M. Arabnejad Khanouki, and M. Mahoutian, "Experimental assessment of angle shear connectors under monotonic and fully reversed cyclic loading in high strength concrete," Construction and Building Materials, vol. 52, pp. 276-283, 2014.

[12] J. P. Lin, J. F. Wang, and R. Q. Xu, "Cohesive zone model based numerical analysis of steel-concrete composite structure push-out tests," Mathematical Problems in Engineering, vol. 2014, Article ID 175483, 2014.

[13] B. Ovuoba and G. S. Prinz, "Fatigue capacity of headed shear studs in composite bridge girders," Journal of Bridge Engineering, vol. 21, no. 12, 2016.

[14] L. N. Dallam, "High strength bolt shear connectors - pushout tests," Am Concrete Inst Journal \& Proceedings, vol. 65, no. 9, pp. 767-769, 1968.

[15] G. Kwon, M. D. Engelhardt, and R. E. Klingner, "Behavior of post-installed shear connectors under static and fatigue loading," Journal of Constructional Steel Research, vol. 66, no. 4, pp. 532-541, 2010.

[16] G. Kwon, M. D. Engelhardt, and R. E. Klingner, "A case study of bridge strengthening through the use of post-installed shear connectors," Structures Congress, pp. 666-675, 2010.

[17] M. Pavlović, Z. Marković, M. Veljković, and D. Buđevac, "Bolted shear connectors vs. headed studs behaviour in pushout tests," Journal of Constructional Steel Research, vol. 88, pp. 134-149, 2013.

[18] M. Pavlović, M. Spremić, Z. Marković, and M. Veljković, "Headed shear studs versus high-strenth bolts in prefabricated composite decks," Composite Construction in Steel and Concrete VII, pp. 687-702, 2016.

[19] J. Su, K. K. Guo, X. M. Hu, and W. Hong, "Experimental study on shear behavior of bolt connectors in prefabricated steel bar truss composite beams," Building Science, vol. 34, no. 11, pp. 67-75, 2018, (in Chinese).

[20] A. Ataei, M. Zeynalian, and Y. Yazdi, "Cyclic behaviour of bolted shear connectors in steel-concrete composite beams," Engineering Structures, vol. 198, pp. 1-15, 2019.

[21] Z. L. Liu, J. Chen, and J. S. Huo, "Experimental study on shear behavior of high strength bolt connection for prefabricated composite beam," Building Structure, vol. 47, no. 10, pp. 64-70, 2017, (in Chinese).

[22] J. Chen, W. Wang, F. X. Ding et al., "Behavior of an advanced bolted shear connector in prefabricated steel-concrete composite beams," Materials, vol. 12, no. 18, 2019.

[23] A. Ataei, M. A. Bradford, and X. P. Liu, "Sustainable composite beams and joints with deconstructable bolted shear connectors," in Proceedings of the23th Australian Conference on the Mechanics of Structures and Materials, pp. 1-6, December,2014.

[24] A. Ataei, M. A. Bradford, and X. Liu, "Experimental study of composite beams having a precast geopolymer concrete slab and deconstructable bolted shear connectors," Engineering Structures, vol. 114, pp. 1-13, 2016.

[25] A. Ataei, M. A. Bradford, and X. Liu, "Experimental study of flush end plate beam-to-column composite joints with precast slabs and deconstructable bolted shear connectors," Structures, vol. 7, pp. 43-58, 2016.

[26] A. Ataei, M. A. Bradford, H. R. Valipour, and X. Liu, "Experimental study of sustainable high strength steel flush end plate beam-to-column composite joints with deconstructable bolted shear connectors," Engineering Structures, vol. 123, pp. 124-140, 2016.

[27] Y.-T. Chen, Y. Zhao, J. S. West, and S. Walbridge, "Behaviour of steel-precast composite girders with through-bolt shear connectors under static loading," Journal of Constructional Steel Research, vol. 103, pp. 168-178, 2014.

[28] X. P. Liu, M. A. Bradford, and M. S. S. Lee, "Behavior of highstrength friction-grip bolted shear connectors in sustainable composite beams," Journal of Structural Engineering, vol. 141, no. 6, 2015.

[29] W. T. Marshall, H. M. Nelson, and H. K. Banerjee, "An experiment Study of the Use of High-Strength Friction Grip Bolts as Shear Connectors in Composite Beams," The Structural Engineer, vol. 49, no. 4, pp. 171-178, 1971.

[30] Y. Zhang, B. Chen, A. Liu et al., "Experimental study on shear behavior of high strength bolt connection in prefabricated steel-concrete composite beam," Composites Part B: Engineering, vol. 159, pp. 481-489, 2019.

[31] O. Mirza and B. Uy, "Effects of the combination of axial and shear loading on the behaviour of headed stud steel anchors," Engineering Structures, vol. 32, no. 1, pp. 93-105, 2010.

[32] C. Xu and K. Sugiura, "Analytical investigation on failure development of group studs shear connector in push-out specimen under biaxial load action," Engineering Failure Analysis, vol. 37, pp. 75-85, 2014.

[33] J. H. Ling, A. B. Ahmad Baharuddin Rahman, I. S. Ibrahim, and Z. Abdul Hamid, "Behaviour of grouted pipe splice under incremental tensile load," Construction and Building Materials, vol. 33, pp. 90-98, 2012.

[34] E. L. Tan, H. Varsani, and F. Liao, "Experimental study on demountable steel-concrete connectors subjected to combined shear and tension," Engineering Structures, vol. 183, pp. 110-123, 2019.

[35] L. Pallarés and J. F. Hajjar, "Headed steel stud anchors in composite structures, Part II: tension and interaction," Journal of Constructional Steel Research, vol. 66, no. 2, pp. 213-228, 2010.

[36] D. Lam, X. H. Dai, and S. Eleonora, "Behaviour of demountable shear connectors in steel-concrete composite beams," Composite Construction in Steel and Concrete VII, pp. 618-631, 2013.

[37] A. Kozma, C. Odenbreit, M. V. Braun, M. Veljkovic, and M. P. Nijgh, "Push-out tests on demountable shear connectors of steel-concrete composite structures," Structures, vol. 21, pp. 45-54, 2019.

[38] A. S. H. Suwaed and T. L. Karavasilis, "Experimental evaluation of a novel demountable shear connector for accelerated repair or replacement of precast steel-concrete composite bridges," Ce/Papers, vol. 1, no. 2-3, pp. 4163-4172, 2017.

[39] A. S. H. Suwaed and T. L. Karavasilis, "Novel demountable shear connector for accelerated disassembly, repair, or replacement of precast steel-concrete composite bridges," Journal of Bridge Engineering, vol. 22, no. 9, pp. 1-18, 2017.

[40] A. Ataei, M. A. Bradford, and H. Valipour, "Sustainable design of deconstructable steel-concrete composite structures," Procedia Engineering, vol. 145, pp. 1153-1160, 2016.

[41] M. C. Moynihan and J. M. Allwood, "Viability and performance of demountable composite connectors," Journal of Constructional Steel Research, vol. 99, pp. 47-56, 2014.

[42] A. Ataei, M. A. Bradford, and H. R. Valipour, "Finite element analysis of HSS semi-rigid composite joints with precast concrete slabs and demountable bolted shear connectors," 
Finite Elements in Analysis and Design, vol. 122, pp. 16-38, 2016.

[43] V. I. Patel, B. Uy, S. W. Pathirana, S. Wood, M. Singh, and B. T. Trang, "Finite element analysis of demountable steelconcrete composite beams under static loading," Advanced Steel Construction, vol. 14, pp. 392-411, 2018.

[44] H. T. Nguyen and S. E. Kim, "Finite element modeling of push-out tests for large stud shear connectors," Journal of Constructional Steel Research, vol. 65, no. 10-11, pp. 19091920, 2009.

[45] M. Abbu, T. Ekmekyapar, and M. Özakça, “3D finite-element analysis of shear connectors with partial interaction," Proceedings of the Institution of Civil Engineers - Structures and Buildings, vol. 169, no. 2, pp. 96-107, 2016.

[46] Q. Han, Y. Wang, J. Xu, Y. Xing, and G. Yang, "Numerical analysis on shear stud in push-out test with crumb rubber concrete," Journal of Constructional Steel Research, vol. 130, pp. 148-158, 2017.

[47] J. Chen, W. Wang, F. X. Ding, F. Xu, S. G. Long, and C. Q. Yang, "Shear bearing capacity of high-strength bolt connectors in steel-concrete composite beams," Journal of Railway Science and Engineering, vol. 16, no. 10, pp. 25532561, 2019, (in Chinese).

[48] X. Liu, M. A. Bradford, Q.-J. Chen, and H. Ban, "Finite element modelling of steel-concrete composite beams with high-strength friction-grip bolt shear connectors," Finite Elements in Analysis and Design, vol. 108, pp. 54-65, 2016.

[49] G. Kwon, M. D. Engelhardt, and R. E. Klingner, "Parametric studies and preliminary design recommendations on the use of postinstalled shear connectors for strengthening noncomposite steel bridges," Journal of Bridge Engineering, vol. 17, no. 2, pp. 310-317, 2012.

[50] A. Ataei and M. A. Bradford, "Numerical study of deconstructable flush end plate composite joints to concrete-filled steel tubular columns," Structures, vol. 8, pp. 130-143, 2016.

[51] GB 50017-2017, Standard for Design of Steel Structures (GB 50017-2017), China Construction Industry Press, Beijing, China, (in Chinese), 2017.

[52] G. Kwon, M. D. Engelhardt, and R. E. Klingner, "Experimental behavior of bridge beams retrofitted with postinstalled shear connectors," Journal of Bridge Engineering, vol. 16, no. 4, pp. 536-545, 2011.

[53] H. Du, X. Hu, Y. Meng, G. Han, and K. Guo, "Study on composite beams with prefabricated steel bar truss concrete slabs and demountable shear connectors," Engineering Structures, vol. 210, Article ID 110419, 2020. 